\title{
Regulation of Natural and Synthetic Estrogens in Drinking Water Bodies: Reviewing Emerging Solutions for an Emerging Problem
}

Fayga Nunes de Albuquerque Pismel

UERJ: Universidade do Estado do Rio de Janeiro

Rosane Cristina de Andrade

UERJ: Universidade do Estado do Rio de Janeiro

Daniele Maia Bila ( $\boldsymbol{\sigma}$ danielebila@eng.uerj.br)

Universidade do Estado do Rio de Janeiro https://orcid.org/0000-0002-7988-0893

\section{Research Article}

Keywords: Endocrine Disruptors Chemicals, Water Quality Criteria, 17a-ethinylestradiol, 17ß-estradiol, estrone, estriol

Posted Date: August 11th, 2021

DOl: https://doi.org/10.21203/rs.3.rs-719233/v1

License: (c) (i) This work is licensed under a Creative Commons Attribution 4.0 International License. Read Full License 


\section{Abstract}

A growing amount of data in the scientific literature indicates that emerging contaminants, such as Endocrine Disruptors Chemicals (EDCs), have increased in concentration in water bodies in recent years. The main objective of this research was to compile data on legal and regulatory frameworks of different locations regarding the control of estrogens (an EDC) in surface and drinking waters, to support regulation in countries where it has not shown significant advances. An analysis was carried out of the legal provisions aimed at guaranteeing the quality of surface and drinking waters, specifically regarding the control of estrogens, in the United States of America (USA), European Union (EU), Australia and Brazil. Among these, it is emphasized that only Australia has reference values for estrogens in water recycling for drinking purposes. Although several scientific data support the harmful effects of estrogens, several countries do not regulate the maximum values of these compounds allowed in water bodies. Some factors can influence the setting of standards for estrogens in regulations, such as the availability of affordable treatment technologies that are proven to be effective in removing these compounds and the lack of robust analytical methods with adequate limits of quantification for detection in low concentrations that can be widely employed.

\section{Highlights}

- Regulations limiting estrogens in drinking water were revised for different countries

- Brazil, European Union and United States have no regulations limiting estrogens in drinking water bodies

- Only Australia has specific regulations for estrogen limits in water recycling

- Australian estrogen limits in water recycling can serve as support for limits in drinking water

\section{Introduction}

The pollution of water bodies can be considered one of the greatest anthropic impacts since the beginnings of human civilization, however, it has increased in recent decades due to the expansion of urbanization and industrialization, reaching limits that make it possible to identify its impacts on both the environment and living beings (Freire et al. 2008). Thus, recalcitrant organic or inorganic substances, often with the potential to bioaccumulate, known as micropollutants, have been gaining prominence due to their risks, even at low concentrations (i.e., in the scale of $\mu \mathrm{g} / \mathrm{L}$ or $\mathrm{ng} / \mathrm{L}$ ). Micropollutants have also been known as "contaminants of emerging concern", chemical compounds or materials that can be found in the environment in trace concentration and with potential risk to human, animal and/or environmental health, and considered "emerging" until there is solid scientific evidence of their potential deleterious effects.

Micropollutants cover a wide range of natural and synthetic compounds, such as steroid hormones, pesticides, herbicides and dioxins. Among them, of great scientific concern and capable of interfering 
with the endocrine system of humans and animals, figure Endocrine Disruptors Chemicals[1] (EDCs) (Birkett and Lester 2003). According to USEPA (2010), EDCs can be defined as exogenous agents that have the ability to interfere with the synthesis, secretion, transport, binding, action or elimination of natural hormones responsible for the maintenance, reproduction, development and behavior of organisms. According to Patel et al. (2020), micropollutants that fall into the EDC category can cause several types of damage to aquatic fauna, such as the feminization of male fish, as well as estrogenic effects in rats. Furthermore, EDCs can have effects on humans, such as increased incidence of breast and testicular cancers, birth defects and decreased sperm count (Birkett and Lester 2003).

Among the various micropollutants classified as EDCs, estrogens stand out, which are considered the most estrogenic EDCs. These hormones, responsible for the development of female characteristics in several living beings, have increased considerably in concentration in aquatic environments in recent decades, drawing the attention of environmental agencies and researchers. For this reason, the natural estrogens $17 \beta$-estradiol, estrone and estriol, compounds excreted daily by animals and humans (Pusceddu et al. 2019) and the synthetic estrogen 17a-ethinylestradiol, a component of some contraceptive pills (Sodré et al. 2007), have been the object of study of recent research.

Estrogens, except for estriol, receive special attention, as they are constantly excreted into the sewage. However, they are not completely removed by conventional methods of primary or even secondary treatment in Sewage Treatment Plants (Bila and Dezotti 2007). Thus, even in countries where sanitation services adequately serve the entire population, these compounds are frequently found in various aqueous matrices, such as rivers, lakes and, occasionally, in drinking water intended for human consumption. In developing countries, such as Brazil, this problem becomes even more accentuated, as there are still several regions where the population is not even served by basic sanitation services, in addition to the frequent problem of clandestine discharge of raw sewage into receiving bodies (Machado et al. 2016).

In the case of Brazil, there are several factors that lead to a deficiency in the sanitation sector, such as the fragmentation of public policies and the lack of regulatory instruments, since there has been no strong sectoral water and sewage policy in the country since the extinction of the National Sanitation Plan, in the late 1980s (Galvão 2009). Scenarios such as this brought to debate among researchers, over the years, the elaboration of legislation and norms aimed at protecting living beings and that are appropriate for the realities of both developed and developing countries (Chaves et al. 2018). Therefore, some countries have started to create a series of deliberations and legal provisions to limit the concentrations of micropollutants in aqueous matrices (da Cunha et al. 2016), but most countries still do not have regulations for this purpose.

The main objective of the present study was to evaluate the legal and normative frameworks regarding the control of estrogens, natural or synthetic, in surface and drinking water in different locations, namely the United States of America (USA), European Union (EU), Brazil and Australia. In so doing, the authors 
hope to offer support to countries that lack regulations concerning the maximum limits of these compounds in surface waters, including for human consumption.

[1] Other names used are: Endocrine Disruptors and hormonally active agents.

\section{Legal Frameworks On The Regulation Of Estrogens In Surface And Drinking Water}

\subsection{United States of America (USA)}

In the United States, the Environmental Protection Agency (USEPA) is the institution responsible for ensuring the quality of water resources and drinking water (USEPA 2020a). Thus, to achieve the proposed objectives of controlling pollution in water bodies, USEPA is supported by the standard known as the Clean Water Act (CWA). The CWA was approved by the U.S. Congress in 1948 and has been updated numerous times over the years. Furthermore, it is the legal reference that establishes the basic structure concerning the control of release of pollutants into the country's aqueous matrices and regulation of the quality standards of its water bodies (USEPA 2020b).

In 1977, Congress decided to make a minor change in the CWA and attached to it a list of toxic pollutants, created one year earlier. This list was intended to be used by states and USEPA to ensure that national water quality criteria and standards would address the problems of toxic contaminants in the country's aqueous matrices. However, the list was not based on individual pollutants, but on the categories of these substances. Then, since its initial objective was not achieved, USEPA created the Priority Pollutant List, which was more effective than the previous one regarding USA regulatory purposes (USEPA 2020c).

In the Water Quality Standards Handbook document, one may find the new list with the modifications concerning water pollutants. Among these updates, some compounds - generated in higher concentrations, with better known effects at the time and that were not yet officially regulated in the United States - were included in the Priority Pollutant List to be regulated in the country (USEPA 1983), for a total of 126 contaminants. Some EDCs are among these pollutants, namely pesticides and their metabolites, phthalates, polycyclic aromatic hydrocarbons and polychlorinated biphenyls (Supplementary Material 1) (Birkett and Lester 2003). It is worth mentioning that no natural or synthetic estrogens are included in this list. However, there was insufficient data to confirm with certainty the risks that these compounds could pose to human health and aquatic environments.

Regarding the objective of guaranteeing the quality of drinking water for human consumption, USEPA is supported by the Safe Drinking Water Act (SDWA), a law approved by the American Congress in 1974 aimed at protecting the health of the population, regulating the public supply of drinking water in the country. The SDWA was updated between 1986 and 1996, including receiving statements concerning actions to protect drinking water and its sources, such as rivers, lakes and reservoirs (USEPA 2020c). The document covers two categories of national regulations, the first of these known as the National Primary 
Drinking Water Regulations (NPDWR). These primary regulations are legally enforceable and aim at limiting concentrations of chemicals and microorganisms with potential adverse effects to human health in drinking water (USEPA 2020d). The second category of regulations is known as the National Secondary Drinking Water Regulations (NSDWR), which are guidelines that limit the concentrations of contaminants that can alter the organoleptic or aesthetic characteristics of drinking water. However, it is worth mentioning that the NSDWR is not of mandatory compliance for water supply systems (USEPA 2020e), i.e., this regulation only establishes maximum desirable values for contaminants in drinking water, and the extrapolation of these values does not result in penalties for distributors.

In this context, in May 2009, National Regulations were issued establishing primary standards for a list of 88 contaminants, such as microorganisms, disinfectants and their by-products, organic and inorganic compounds and radioactive nucleotides. Estrogens are not included in the list, but some EDCs figure in it, including pesticides, herbicides and phthalates, which were included due to harmful effects other than endocrine disruption (USEPA 2009). Thus, as part of the system for assessing the risk of contaminants to human health, USEPA has a drinking water monitoring program for substances that are not yet included in this list of contaminants. The program is known as Unregulated Contaminant Monitoring (UCM) (USEPA 2020f), and through it, a list of substances that are not yet subject to regulation but that may be present in water is periodically published. This list is known as the Contaminant Candidate List (CCL). The SDWA specifies that USEPA includes in the list contaminants that pose a risk to human health due to their presence in drinking water. Therefore, the CCL is used to identify priority pollutants for regulatory decision-making (USEPA, 2020g).

The first of the CCLs (CCL1) was published in 1998 and included 50 chemicals and 10 microorganisms. In 2005, CCL2 was published, comprising the exclusion of 9 contaminants (1 microorganism and 8 chemical substances), reducing the list to 51 contaminants. The most substantial changes were observed in the change from CCL2 to CCL3, the latter published in 2009, and which included contaminants from several different chemical classes, as well as microorganisms, and expanded the list to 116 contaminants, including pesticides, commercial chemicals, disinfection by-products, drugs and microorganisms. In the CCL3, the estrogens 17a-ethinylestradiol, 17 $\beta$-estradiol, estrone and estriol were included, in addition to other EDCs, for instance pesticides, herbicides and drugs such as nonylphenol surfactant, tribuphos and 19-noretestosterone. Also concerning the changes made between CCL2 and CCL3, the exclusion of 24 chemical compounds and 7 microorganisms stands out.

Finally, between CCL3 and the most recent CCL4, published in 2016, estriol, estrone, 17a-ethinylestradiol and $17 \beta$-estradiol were maintained on the list and 4 more chemicals substances were included, such as a well-known ED, nonylphenol. Moreover, 7 chemical compounds were excluded. It is worth noting that the compounds present in the initial list are 1,1,2,2-tetrachloroethane, 1,1-dichloroethane, 2,4,6trichlorophenol, Acetochlor, Alachlor ethanesulfonic acid (ESA), Diuron, Methyl bromide (Bromomethane), Methyl tert-butyl ether, Metolachlor, Nitrobenzene, RDX (Hexahydro-1,3,5-trinitro-1,3,5-triazine) and Vanadium, while the microorganisms comprise Adenoviruses, Caliciviruses and Mycobacterium avium. Currently, a CCL5 is being prepared by USEPA, and the contributions of a Public Consultation that was 
carried out are under evaluation. It is noteworthy that the CCL5 was not considered in this study because it is still under development (USEPA, 2020g).

Fig 1 shows the year of publication of each of the CCL, as well as the substances considered as priority, with a focus on the situation of EDCs.

After the release of a CCL, the USEPA reviews available data on all listed contaminants and determines which ones have sufficient information to be evaluated based on three SDWA criteria: possibility of adverse effects on human health; frequency of occurrence in public water systems; and, if the contaminant is regulated, whether there is a significant opportunity to reduce its health risks (da Cunha et al. 2016). If a particular contaminant meets these three SDWA criteria, the law requires USEPA to periodically decide whether to initiate a national drinking water regulatory process for at least five CCL contaminants. This process is known as Regulatory Determination.

Until this moment, four Regulatory Determinations have been published but none of them includes estrogens (USEPA, 2020g). According to USEPA, despite their known harmful effects on the health of aquatic environments, there is still no solid scientific basis to safely confirm their harmful effects on human health. In the absence of such solid evidence, it is understood that the Precautionary Principle, established by the Conference on the Environment and Development (Rio-92), should be maintained, since there is no absolute scientific certainty that these contaminants pose no risks to human health and the environment (Editor 1992).

Thus, it is possible to conclude that, although estrogens are not yet considered in legal provisions as priority substances for regulation in the USA, these EDCs have gained attention in the country over the years, in order to guarantee the quality of its surface waters. Since 2009 , both the synthetic (17aethinylestradiol) and natural (17ß-estradiol, estrone and estriol), have been included in the drinking water monitoring programs for unregulated compounds.

\subsection{European Union}

In the European Union, the management of water resources is more complex than in the United States of America, mainly due to its geopolitical structure, as approximately $60 \%$ of its surface is formed by river basins that cross at least one national border, i.e., many countries share the same water bodies. Thus, in order to obtain an efficient management of water resources, Member States sought an integrated solution that could protect their aqueous matrices (European Commission 2008).

In this context, in 2000, Directive 2000/60/EC, known as the Water Framework Directive (WFD) (European Commission 2020), was drafted with the aim of protecting and improving the quality of aquatic ecosystems in Europe and ensuring sustainable water consumption over the years. This directive addresses water management based on river basins and stipulates deadlines for Member States to protect their water resources (European Union 2000). Therefore, as a measure for preserving aquatic 
ecosystems, in 2001, Decision 2455/2001/EC was issued, amending Directive 2000/60/EC and establishing a list of 33 priority substances to be included in the legislation (European Union 2001). This list comprises some EDCs such as phthalates and pesticides.

In 2012, the European Commission published the document COM (2011)876, which presents a proposal to include 15 new compounds in the list of priority substances (European Union 2012). The selection of these new compounds was based on substances identified as a potential risk to aquatic ecosystems, and two estrogens were selected, the synthetic estrogen 17a-ethinylestradiol and the natural estrogen $17 \beta$ estradiol. Furthermore, in this document, maximum concentrations of these substances in surface water were proposed, namely $0.035 \mathrm{ng} / \mathrm{L}$ for $17 \mathrm{a}$-ethinylestradiol and $0.4 \mathrm{ng} / \mathrm{L}$ for $17 \beta$-estradiol (European Union 2012).

After several discussions regarding the inclusion of these 15 new substances in legislation aimed at ensuring the quality of surface water, in 2013, the European Union issued Directive 2013/39/EU65, which approved the insertion of 12 of the 15 proposed substances (European Union 2013), without the inclusion of estrogens. However, 17a-ethinylestradiol, 17ß-estradiol and estrone were included in the watch list published in Executive Decision 2015/495, so that more monitoring data for these compounds in surface waters could be collected (European Union 2015). Subsequently, in 2018, this decision was repealed and replaced by a new watch list, Executive Decision 2018/840. In it, 17a-ethinylestradiol, 17ß-estradiol and estrone have been kept, although they are not yet included in surface water quality monitoring legislation (European Union 2018).

Aiming to guarantee the quality of drinking water to the Member States, Directive 98/83/EC was issued in 1998 , aimed at protecting human health from the harmful effects resulting from any contamination in the water and ensuring its quality for human consumption. Thus, this directive determines that 48 parameters - microbiological, chemical and indicator ones - must be evaluated (European Union 1998). Ten years later, the European Commission understood that it would be necessary to update the directive so that it could continue to establish water quality standards, in accordance with the current recommendations of the World Health Organization (WHO). Therefore, in 2018, the Commission published the document COM (2017)753, which presents a proposal to revise Directive 98/83/EC (Council of the European Union 2020a). In 2020, the proposal presented in the aforementioned document was formally accepted by the European Parliament. The directive 2020/2184 entered into force in 2021 (European Commission, 2020b), and Member States currently have 2 years to adopt the new measures imposed in this legislation. It is worth noting that COM (2017)753 proposed the inclusion of three EDCs in Directive 2020/2184, namely $17 \beta$-estradiol, noniphenol and bisphenol A, but only bisphenol A is expected to be included. Noniphenol and $17 \beta$-estradiol should be added to the European Union watch list if more monitoring data are to be obtained (Council of the European Union 2020b).

Finally, regarding the regulation of estrogens in the European Union, it can be concluded that, as far as we know, none of its countries currently has regulations establishing their maximum permitted concentrations in water intended for human consumption. As for the regulation of surface water, 
estrogens are not yet part of the directives that aim at ensuring the quality of their water sources, but they were included in a watch list so that more data could be collected, as stated in Executive Decision 2018/840 (European Union 2018). Fig 2 shows the year of publication of each of the lists mentioned above, as well as the substances considered as priorities, with a focus on the situation of EDCs.

\subsection{Australia}

Water resource management in Australia is even more complex than in the USA and EU, since it has a vast territorial extension, with varied climatic zones and local particularities. In addition, with its predominantly dry climate, Australia has two deserts (Gibson and Victoria) and has already undergone the greatest drought recorded in its territory. Thus, in order to facilitate the country's water management, in 1960, the Australian Water Resources Council (AWRC) divided the country into twelve hydrographic regions based on their main topographical and climatic characteristics (WQA 2020a).

Since 1974, concern in ensuring the quality of water resources in Australia has increased. Then, under the direction of the AWRC, the first Australian Water Quality Guidelines were published. In 1992, the Australia and New Zealand Environment and Conservation Council (ANZECC) developed new guidelines related to water quality, the Australian and New Zealand Guidelines for Fresh and Marine Water Quality, whose main objective was the orientation of both countries in the better management of their water bodies (WQA 2020b).

In 2000, the ANZECC re-examined its guidelines, together with the Agriculture and Resource Management Council of Australia and New Zealand (ARMCANZ), to include the most current scientific information, ensuring that it complements the government's sustainable resource development initiatives and promoting a more holistic approach to the management of aquatic ecosystems (Anzecc and Armcanz 2000). In these guidelines, there is a list of 255 substances that are harmful to aquatic ecosystems, as well as their maximum concentrations. Some EDCs - but not estrogens - figure among these substances, such as polychlorinated biphenyls, phthalates, dioxins and pesticides.

Currently, the Australian and New Zealand Guidelines for Fresh and Marine Water Quality provide guidance on water resources management, ecological descriptions and regional standard values for just three of Australia's twelve hydrographic regions (Timor Sea, Indian Ocean and Gulf of Carpentaria). However, it is worth noting that, until now, these data were not disclosed on the website of Water Quality Australia (WQA) and that, according to the WQA (2020a), information for the other nine hydrographic regions in Australia is still in development stages.

The National Health and Medical Research Council (NHMRC), one of the main public bodies in Australia, responsible for funding health research, played a fundamental role in ensuring the quality of drinking water to the country's population. In 2011, the NHMRC, together with the Natural Resource Management Ministerial Council (NRMMC), wrote the document entitled Australian Drinking Water Guidelines (ADWG) (NHMRC; NRMMC 2011). This document is intended to provide a solid foundation for the 
Australian community and the water supply industry on defining safe and healthy water, and how it can be achieved and guaranteed. The ADWG lists the maximum permitted concentrations of some chemical substances in drinking water. According to the ADWG, EDCs are not included among these, as their concentrations in water supply systems are insignificant compared to other sources of estrogenic activity (NHMRC; NRMMC 2011).

In addition to the ADWG, Australia is supported by the guidelines entitled Australian National Guidelines for Water Recycling (EPCH; NHMRC; NRMMC 2008), created with the aim of providing guidance on the use of water recycling to supplement the supply of drinking water. However, nowadays, these guidelines provide reference values for the concentrations of various pollutants in drinking water. The Australian National Guidelines for Water Recycling also comprise a list of 225 chemical substances, their maximum concentrations and their reference values in treated sewage for reuse (EPCH; NHMRC; NRMMC 2008). Some EDCs figure among these substances, including dioxins, pharmaceuticals, pesticides and natural and synthetic estrogens Furthermore, it was found that the reference value set to 17a-ethinylestradiol (1.5 $\mathrm{ng} / \mathrm{L}$ ) in Australian National Guidelines for Water Recycling is considerably below the maximum permissible concentrations of 17ß-estradiol, estrone and estriol ( $175 \mathrm{ng} / \mathrm{L}, 30 \mathrm{ng} / \mathrm{L}$ and $50 \mathrm{ng} / \mathrm{L}$, respectively) (EPCH; NHMRC; NRMMC 2008).

Finally, regarding the regulation of estrogens in Australia, it can be concluded that, so far, these substances are not part of the norms that aim at guaranteeing the quality of its surface waters. However, the country does have its national guidelines, which establish the maximum permitted concentrations of estrogens in water recycling and are used to supplement the supply of drinking water (EPCH; NHMRC; NRMMC 2008). These concentrations can support the regulation of these compounds both in Australian surface and drinking waters, as well as in the waters of other countries that do not yet have wellestablished limits. Fig 3 presents the year of publication of each of the cited documents, as well as the year of inclusion of estrogens in them and their maximum limits.

\subsection{Brazil}

In Brazil, the main legal provisions intended to ensure the quality of water bodies are under the responsibility of the Ministry of the Environment (MMA). Through the National Council for the Environment (CONAMA), the MMA establishes a series of resolutions, which are mandatory at the national level, in order to achieve the objective of maintaining the quality of the country's water resources.

In this context, in 2005, CONAMA Resolution $n^{\circ} 357$ (Brazil 2005) was issued. This resolution deals with the classification of water bodies and the environmental guidelines for their classification, and also presents a list of chemical substances and their maximum values allowed in surface waters, including some EDCs, such as polycyclic aromatic hydrocarbons and pesticides, but no estrogens (Brazil 2005). It is important to emphasize that the resolution aims at guaranteeing the quality of Brazil's water bodies, as well as providing a technical basis for its decision makers to define water quality standards. However, 
approximately fifteen years after the resolution was issued, little progress has been observed in ensuring the quality of national water bodies.

Regarding the objective of guaranteeing the quality of drinking water to the population, Brazil has the support of the Ministry of Health, which, according to Decree $n^{\circ} 79.367$ of 1977, establish drinking water norms and standards of water for human consumption, in compliance with national agencies and entities (Brazil 1977). Thus, in 1977, Ordinance $n^{\circ} 56$ was issued. This was the first legal provision in the country aimed at guaranteeing the potability of water, considering physical, chemical and microbiological parameters, as well as changes in its organoleptic characteristics, in order to ensure adequate standards. In addition, the regulation included the Maximum Allowable Values and the Maximum Desirable Values for the physical and chemical parameters of potability (Brazil, 2011a).

On January 19,1990 , Ordinance $n^{\circ} 36$ was issued, changing and replacing its predecessor, Ordinance $n^{\circ}$ 56. Among the changes, it is possible to verify the revision of some definitions at the beginning of the text and the introduction of new items, of which the extinction of the Maximum Desirable Values criteria stands out (Brazil 1990). Ten years later, Ordinance $n^{\circ} 36$ of 1990 was revised and replaced by Ordinance $n^{\circ} 1469$, of December 29, 2000, which establishes procedures and responsibilities for the control and surveillance of the quality of water for human consumption and provides standards of potability (Brazil 2000).

In 2004, Ordinance $n^{\circ} 518$ entered into force. A legal provision based on the guidelines of the 3 rd edition of the WHO Water Quality Guidelines for Human Consumption, it presents: a systemic and integrated view of the entire system, i.e., from the source to the point of consumption, in order to guarantee the quality of the water; fundamentals of good practice; an epidemiological perspective and the population's right to information (Brazil 2004).

In 2011, Ordinance $n^{\circ}$ 2,914 (Brazil, 2011b) entered into force, establishing drinking water standards and the procedures and responsibilities for the control and surveillance of the quality of drinking water. This legal provision was developed during the review of the repealed Ordinance $n^{\circ} 518$ of 2004 and was based on the guidelines of the 4th Edition of the WHO Water Quality Guidelines for Human Consumption, in addition to some international legislation, such as those of the EU, USA and Canada. This ordinance establishes water quality standards for microorganisms, cyanotoxins, radionuclides and various chemical compounds, including pesticides, disinfectants and disinfection by-products, as well as some potential EDCs, such as polycyclic aromatic hydrocarbons, phthalates and pesticides.

In 2017, the Ministry of Health consolidated the rules on the actions and health services of the Unified Health System, and Ordinance $n^{\circ} 2,914 / 2011$ became Annex XX of Consolidation Ordinance $n^{\circ} 5$, of September 28, 2017 (Brazil 2017), with all its content kept in full. Currently, Ordinance GM/MS n 888 of May 2021 (Brazil 2021) is the most recent legal provision providing control and surveillance procedures for the quality of water for human consumption and its potability standards, thus changing the Annex XX of Consolidation Ordinance $\mathrm{GM} / \mathrm{MS} \mathrm{n}^{\circ} 5$. It is worth noting that estrogens were not included in the last 
two amendments to the ordinances. However, Annex XX of 2017 was the first review process that considered the possibility of including drugs and EDCs in potability standards (Brazil 2020).

It is important to emphasize that, in 2012, the Brazilian Association of Sanitary and Environmental Engineering - São Paulo Section (ABES/SP) published a document entitled Potability Guide for Chemical Substances, a significant contribution in the assessment of risk to human health in water consumed by the residents of the state of São Paulo. At the beginning of its elaboration, based on scientific literature, 291 substances were selected according to their function, quantity produced, persistence and their effects on the environment, in order to improve the list of priority substances (Umbuzeiro 2012). Also, according to the document published by ABES/SP (2012), after adjustments made to the main list, only 72 substances were selected to be a part of the list of substances proposed as priority for the state of São Paulo. Although estrogens (17a-ethinylestradiol, 17 $\beta$-estradiol, estrone) were included in the first stage of selection of the 291 compounds, they were excluded from this final list, since the assessment of the toxicity of these substances does not yet allow the establishment of reference doses and, therefore, it is not possible to establish water quality criteria for them (Umbuzeiro 2012).

Regarding the regulation of estrogens in Brazil, it can be concluded that, so far, these substances were not included in regulations designed to guaranteeing the quality of surface and drinking water.

Table 1 summarizes the different regulations in the USA, EU, Australia and Brazil, in order to guarantee the quality of surface and drinking waters over the years.

Table 1. Regulations in order to guarantee the quality of surface and drinking waters in the USA, European Union, Australia and Brazil. 


\section{Regulation}

\section{United States of America}

Clean Water Act

Water Quality Standards Handbook

Safe Drinking Water Act

Unregulated Contaminant Monitoring; Contaminant Candidate List

\section{European Union}

Directive 2000/60/EC - Water Framework Directive

Decision 2455/2001/EC

“COM (2011)876"

Directive 2013/39/EU65

Execution Decision 2015/495

Execution Decision 2018/840

“COM (2017)753"

\section{Australia}

$1^{\text {st }}$ Australia's Water Quality Guidelines

Australian and New Zealand Guidelines for Fresh and Marine Water Quality

Australian National Guidelines for Water Recycling

Australian Drinking Water Guidelines

\section{Brazil}

Decree $n^{\circ} 79.367$ - Ministry of Health

Ordinance $n^{\circ} 36$

Ordinance $n^{\circ} 1469$

Ordinance $n^{\circ} 518$

CONAMA Resolution $n^{\circ} 357$

Ordinance $n^{\circ} 2,914$

Annex XX of Consolidation Ordinance $n^{\circ} 5$,
Year Reference

1948 USEPA (2020b)

1983 USEPA (1983)

1974 USEPA (2020c)

2009 USEPA (2009)

2000 European

Commission (2020b)

2001 European Union (2001)

2012 European Union (2012)

2012 European Union (2013)

2015 European Union (2015)

2018 European Union (2018a)

2018 Maiti and

Bidinger (2018)

1974 WQA(2020a)

1994 WQA (2020b)

2008 EPCH; NHMRC;

NRMMC (2008)

2011 NHMRC; NRMMC (2011)

1977 Brazil (1977)

1990 Brazil (1990)

2000 Brazil (2000)

2004 Brazil (2004)

2005 Brazil (2005)

2011 Brazil (2011b)

2017 Brazil (2017) 
Water Quality Guidelines for Human Consumption Ordinance $\mathrm{GM} / \mathrm{MS} \mathrm{n}^{\circ} 888$
2020

2021
Umbuzeiro (2012)

Brazil (2021)

It is worth noting that the present research covered the regulations of only four countries/regions, since information on regulations related to estrogens in other countries is still scarce. According to Liu et al. (2021), in Japan, the maximum recommended values for 17ß-estradiol and 17a-ethinylestradiol in drinking water are, respectively, $0.08 \mu \mathrm{g} / \mathrm{L}$, and $0.02 \mu \mathrm{g} / \mathrm{L}$. In China, there are maximum limits for di-butyl phthalate $(3 \mu \mathrm{g} / \mathrm{L})$, adipate $(400 \mu \mathrm{g} / \mathrm{L})$, di-ethyl phthalate $(300 \mu \mathrm{g} / \mathrm{L})$ and bisphenol $(10 \mu \mathrm{g} / \mathrm{L})$ compounds. According to the same authors, some countries also have established maximum values for the presence of phthalates (potential EDCs) in drinking water. The following were cited: Australia (10 $\mu \mathrm{g} / \mathrm{L})$, Israel $(8 \mu \mathrm{g} / \mathrm{L})$, South Korea $(8 \mu \mathrm{g} / \mathrm{L})$, New Zealand $(9 \mu \mathrm{g} / \mathrm{L})$, Oman $(8 \mu \mathrm{g} / \mathrm{L})$, Philippines $(8 \mu \mathrm{g} / \mathrm{L})$, Singapore $(8 \mu \mathrm{g} / \mathrm{L})$ and USA $(6 \mu \mathrm{g} / \mathrm{L})$. The BPA compound, in turn, has limit values established in China $(10 \mu \mathrm{g} / \mathrm{L})$, Japan $(100 \mu \mathrm{g} / \mathrm{L})$ and the USA $(2.5 \mu \mathrm{g} / \mathrm{L})$.

\section{Final Considerations}

Based on a survey of the legal and normative frameworks concerning the control of natural and synthetic estrogens in different localities, it was possible to conclude that, until the present moment, no maximum limits to these compounds were established, neither for water intended for human consumption, nor for surface waters.

Throughout the years, estrogens were included in environmental programs that monitor contaminants that present a potential risk to human health and aquatic ecosystems, in order to investigate their presence/concentration in surface and potable waters, as well as identifying priority pollutants subject to regulation. Since 2009, in the USA, estrogens are included in the CCL (CCL3). However, they were not included in the last regulations for potable waters approved in the country. In the EU, since 2012, a proposition was made for including the estrogens $17 \beta$-estradiol and 17a-ethinylestradiol in the PPL, along with their maximum allowed values (or limiting values) in surface waters $(0,4 \mathrm{ng} / \mathrm{L}$ and $0,035 \mathrm{ng} / \mathrm{L}$, respectively). Still, these compounds were not included as regulated priority pollutants in the most recent directive intended for ensuring the quality of water, be it a surface one or intended for human consumption. In Australia, limiting values were established for natural and synthetic estrogens in regulations concerning reuse water intended for human supply $(1.5 \mathrm{ng} / \mathrm{L}, 175 \mathrm{ng} / \mathrm{L}, 30 \mathrm{ng} / \mathrm{L}$ and $50 \mathrm{ng} / \mathrm{L}$ for $17 \mathrm{a}$-ethinylestradiol, $17 \beta$-estradiol, estrone and estriol, respectively). However, these compounds have not yet been included in regulations for surface and potable waters in the country. In Brazil, although potable water regulations have undergone several revisions, estrogens and other EDCs were investigated for the first time for establishing their limiting values only in 2017, but none of these compounds were included in the most recent brazilin regulation. In this context, despite the occurrence of estrogens in 
water sources and their deleterious effects in very low concentrations being reported widely in the scientific literature, these compounds were not included in the regulations aiming at guaranteeing the quality of potable water and its sources in any country. Nevertheless, there are maximum values established for other EDCs in water regulations, such as bisphenol A in the European Union and DEHP and DHEA in the United States. This suggests that regulation for these compounds in potable water is region-specific, with no existent universal guideline.

The documentation related to legislation indicates that there is still not enough scientific data proving that the estrogen concentrations found in potable water sources intended for human supply present a potential risk to human health, so as to sustain their inclusion as priority pollutants in potable water regulations. However, other factors may be influencing the absence of maximum allowed values for these compounds in these regulations. One such factor may be the availability of cheap water treatment technologies, able to efficiently remove these compounds from potable water and wastewater; on the other hand, robust analytical methods, able to adequately detect pollutants and that do not carry excessive costs (which would prevent their widespread use in laboratories), would allow measuring them in water sources. In light of this, we believe that scientific and technological advances that sustain criteria for the inclusion of estrogens in regulations must be sought, so that water quality standards more in line with the current scenario may be implemented.

\section{Declarations}

\section{Acknowledgements}

The authors acknowledge the financial support granted by Fundação de Amparo à Pesquisa do Estado do Rio de Janeiro - FAPERJ (No. E-26/010.002251/2019) and Conselho Nacional de Desenvolvimento Científico e Tecnológico - CNPq (No. 311100/2018-0) in the scope of this research.

Ethics approval and consent to participate

Not applicable

\section{Consent for publication}

Not applicable

\section{Availability of data and materials}

Not applicable. Data sharing is not applicable to this article as no datasets were generated or analyzed during the current study

Competing interests

The authors declare that they have no competing interests 


\section{Funding}

- Fundação de Amparo à Pesquisa do Estado do Rio de Janeiro - FAPERJ (No. E26/010.002251/2019);

- Conselho Nacional de Desenvolvimento Científico e Tecnológico - CNPq (No. 311100/2018-0).

Authors' contributions: All authors read and approved the final manuscript.

- FNA Pismel: Conceptualization; Methodology; Formal analysis; Investigation; Writing - Original Draft; Visualization.

- RC Andrade: Conceptualization; Methodology; Resources; Data Curation; Writing - Review \& Editing; Supervision; Project administration.

- DM Bila: Conceptualization; Methodology; Resources; Data Curation; Writing - Review \& Editing; Supervision; Project administration; Funding acquisition.

\section{References}

1. Anzecc, Armcanz (2000) Australian and New Zealand guidelines for fresh and marine water quality The Guidelines Australian and New Zealand Environment and Conservation Council Agriculture and Resource Management Council of Australia and New Zealand. Natl Water Qual Manag Strateg 1:314

2. Bila DM, Dezotti M (2007) Endocrine disrupters in the enviroment: part 1 - effects and consequences. Quim Nova 30:651-666. https://doi.org/10.1590/S0100-40422007000300027 (in Portuguese)

3. Birkett JW, Lester JN (2003) Endocrine Disrupters in Wastewater and Sludge Treatment Processes

4. Brazil (2005) National Council for the Environment. Resolution CONAMA $n^{\circ}$. 357, de 17 de março de 2005. Brazil, Brasília (in Portuguese)

5. Brazil (1977) Decreto n . 79.367, de 9 de março de 1977. Brazil, Brasília (in Portuguese)

6. Brazil (2011a) Base Document for the Elaboration of Ordinance No. 2.914/2011: "Ordinance on Drinking Water for Human Consumption". Ministério da Saúde, Brazil, Brasília (in Portuguese)

7. Brazil (1990) Portaria nº. 36, de 19 de janeiro de 1990. Ministério da Saúde, Brazil, Brasília (in Portuguese)

8. Brazil (2000) Portaria $\mathrm{n}^{\circ}$. 1469, de 29 de dezembro de 2000. Ministério da Saúde, Brazil, Brasília (in Portuguese)

9. Brazil (2004) Portaria n. 518, de 25 de março de 2004. Ministério da Saúde, Brazil, Brasília

10. Brazil (2011b) Portaria n. 2914, de 12 de dezembro de 2011. Ministério da Saúde, Brazil, Brasília (in Portuguese)

11. Brazil (2017) Portaria de Consolidação $n^{\circ} .5$, de 28 de setembro de 2017. Consolidation of norms on the actions and health services of the Unified Health System. Ministério da Saúde, Brazil, Brasília (in Portuguese) 
12. Brazil (2020) Consulta Pública $n^{\circ} .3$, de 03 de março de 2020. Ministério da Saúde

13. Brazil M da S (2021) Portaria GM/MS n 888 de 4 de maio de 2021. Official Journal of the Union, Brasília (DF) (in Portuguese)

14. Chaves VS, Schneider EHM, Lima ASP, Mendonça LC (2018) Performance of Sewage Treatment Plants in Aracaju. Rev DAE 66:51-58. https://doi.org/10.4322/dae.2017.014 (in Portuguese)

15. Council of the European Union (2020a) Proposal for a Directive of the European Parliament and of the Council on the quality of water intended for human consumption (recast) - Political agreement. Brussels

16. Council of the European Union (2020b) Decisão de Execução (UE) 2020/2181 da Comissão. Official Journal of the European Communities, Brussels

17. da Cunha DL, Camargo da Silva SM, Bila DM, et al (2016) Regulation of synthetic estrogen 17aethinylestradiol in aquatic matrices in Europe, United States and Brazil. Cad Saude Publica 32:1-12. https://doi.org/10.1590/0102-311X00056715 (in Portuguese)

18. Editor (1992) Rio de Janeiro's Declaration. Estud Avançados 6:153-159. https://doi.org/10.1590/s0103-40141992000200013 (in Portuguese)

19. EPCH; NHMRC; NRMMC (2008) Australian Guidelines for Water Recycling (Phase 2): Augmentation of Drinking water supplies. Biotext Pty Ltd, Canberra

20. European Commission (2008) Notes on Water relating to the implementation of the Water Framework Directive. From rivers to sea: Link to the new marine strategy framework directive (in Portuguese)

21. European Commission (2020) The EU Water Framework Directive - Integrated river basin management for Europe

22. European Union (2000) Directiva 2000/60/CE do Parlamento Europeu e do Conselho, de 23 de outubro de 2000. Official Journal of the European Communities

23. European Union (2001) Decisão 2455/2001/CE do Parlamento Europeu e do Conselho

24. European Union (2012) Proposta de Directiva do Parlamento Europeu e do Conselho, de 31 de janeiro de 2012. Official Journal of the European Communities

25. European Union (2013) Directiva 2013/39/UE do Parlamento Europeu e do Conselho, de 12 de agosto de 2013. Official Journal of the European Communities

26. European Union (2015) Decisão de Execução (UE) 2015/495 da Comissão, de 20 de março de 2015. Official Journal of the European Communities

27. European Union (2018) Decisão de Execução (UE) 2018/840 da Comissão, de 5 de junho de 2018. Official Journal of the European Communities

28. European Union (1998) Directiva 98/83/CE do Conselho, de 3 de novembro de 1998. Official Journal of the European Communities

29. Freire MM, Santos VG, Ginuino ISF, Arias ARL (2008) Biomarkers in Environmental Health Assessment of Aquatic Ecosystems. Oecologia Aust 12:347-354. 
https://doi.org/10.4257/oeco.2008.1203.01 (in Portuguese)

30. Galvão AC (2009) Challenges for the universalization of water and sewage services in Brazil. Rev Panam Salud Publica/Pan Am J Public Heal 25:548-556. https://doi.org/10.1590/s102049892009000600012 (in Portuguese)

31. Liu Z hua, Dang Z, Liu Y (2021) Legislation against endocrine-disrupting compounds in drinking water: essential but not enough to ensure water safety. Environ Sci Pollut Res.

https://doi.org/10.1007/s11356-021-12901-1

32. Machado KC, Grassi MT, Vidal C, et al (2016) A preliminary nationwide survey of the presence of emerging contaminants in drinking and source waters in Brazil. Sci Total Environ 572:138-146. https://doi.org/10.1016/j.scitotenv.2016.07.210

33. Maiti, Bidinger (2018) Proposal for a Directive of the European Parliament and of the Council on the quality of water intended for human consumption (recast). J. Chem. Inf. Model. 1689-1699

34. NHMRC; NRMMC (2011) Australian Drinking Water Guidelines Paper 6 National Water Quality Management Strategy, 3.5. Camberra

35. Patel N, Khan MZA, Shahane,S., et al (2020) Emerging Pollutants in Aquatic Environment: Source, Effect, and Challenges in Biomonitoring and Bioremediation- A Review. 6:99-113. https://doi.org/10.22059/poll.2019.285116.646

36. Pusceddu FH, Sugauara LE, de Marchi MR, et al (2019) Estrogen levels in surface sediments from a multi-impacted Brazilian estuarine system. Mar Pollut Bull 142:576-580. https://doi.org/10.1016/j.marpolbul.2019.03.052

37. Sodré FF, Montagner CC, Locatelli MAF, Jardim WF (2007) Occurrence of Endocrine Interferences and Pharmaceutical Products in Surface Waters in the Region of Campinas (SP, Brazil). J Brazilian Soc Ecotoxicol 2:187-196. https://doi.org/10.5132/jbse.2007.02.012 (in Portuguese)

38. Umbuzeiro G de A (2012) Potability guide for chemical substances. Ed. Limiar, São Paulo (in Portuguese)

39. USEPA (2010) Endocrine Disruptor Screening Program: Second List of Chemicals for Tier 1 Screening

40. USEPA (2020a) Our Mission and What We Do

41. USEPA (2020b) Summary of the Clean Water Act

42. USEPA (2020c) Overview of the Safe Drinking Water Act

43. USEPA (1983) Water Quality Standards Handbook: Appendix $P$

44. USEPA (2020d) National Primary Drinking Water Regulations

45. USEPA (2020e) Drinking Water Regulations and Contaminants

46. USEPA (2009) National Primary Drinking Water Regulation Table

47. USEPA (2020f) Drinking Water Contaminant Candidate List (CCL) and Regulatory Determination

48. WQA (2020a) Australia's inland waters

49. WQA (2020b) History of the Water Quality Guidelines 


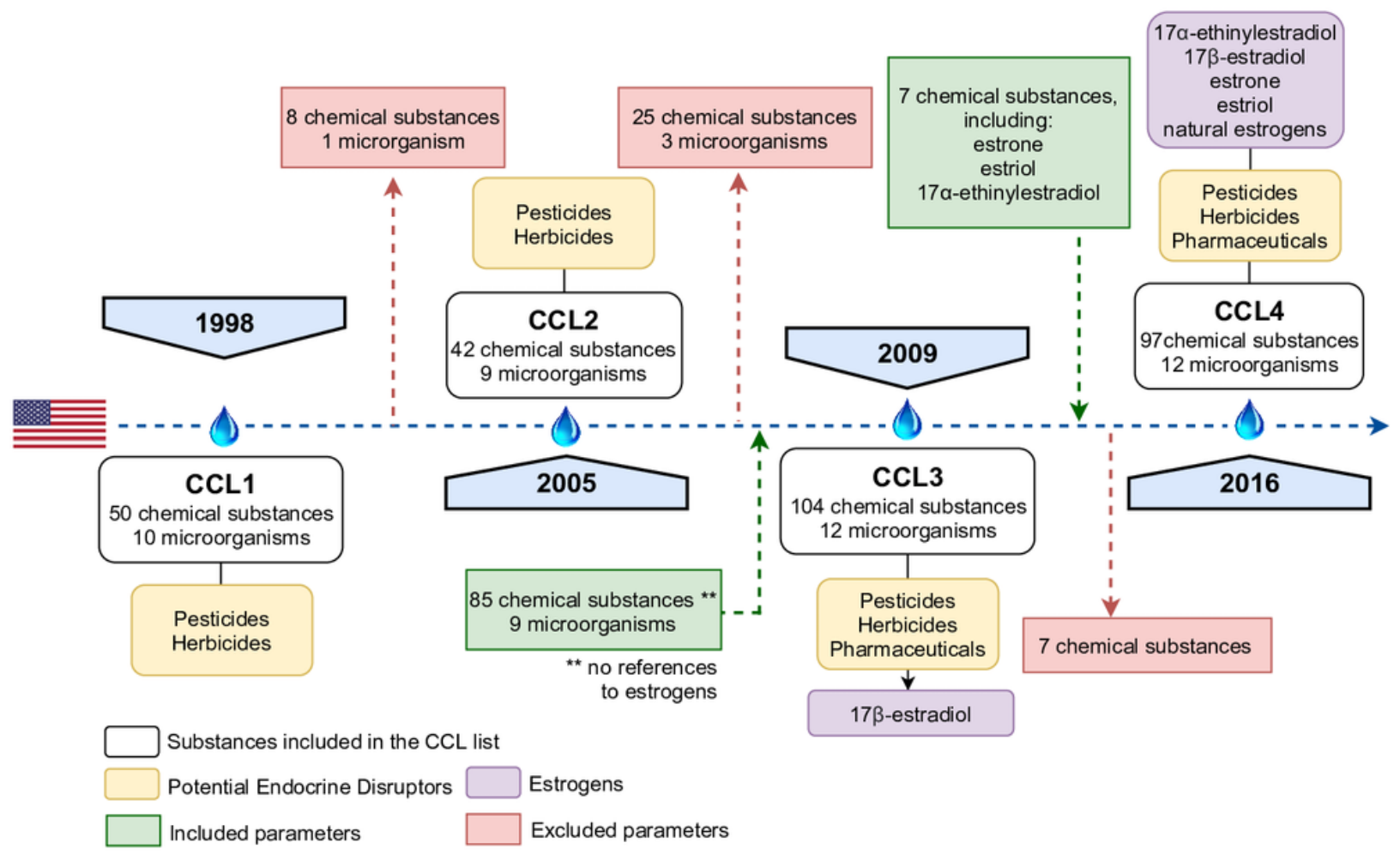

Figure 1

Timeline for substances included in CCLs published in 1998, 2005, 2009 and 2016 and status of EDCs on each of these lists Source: data available from USEPA (2020g). 


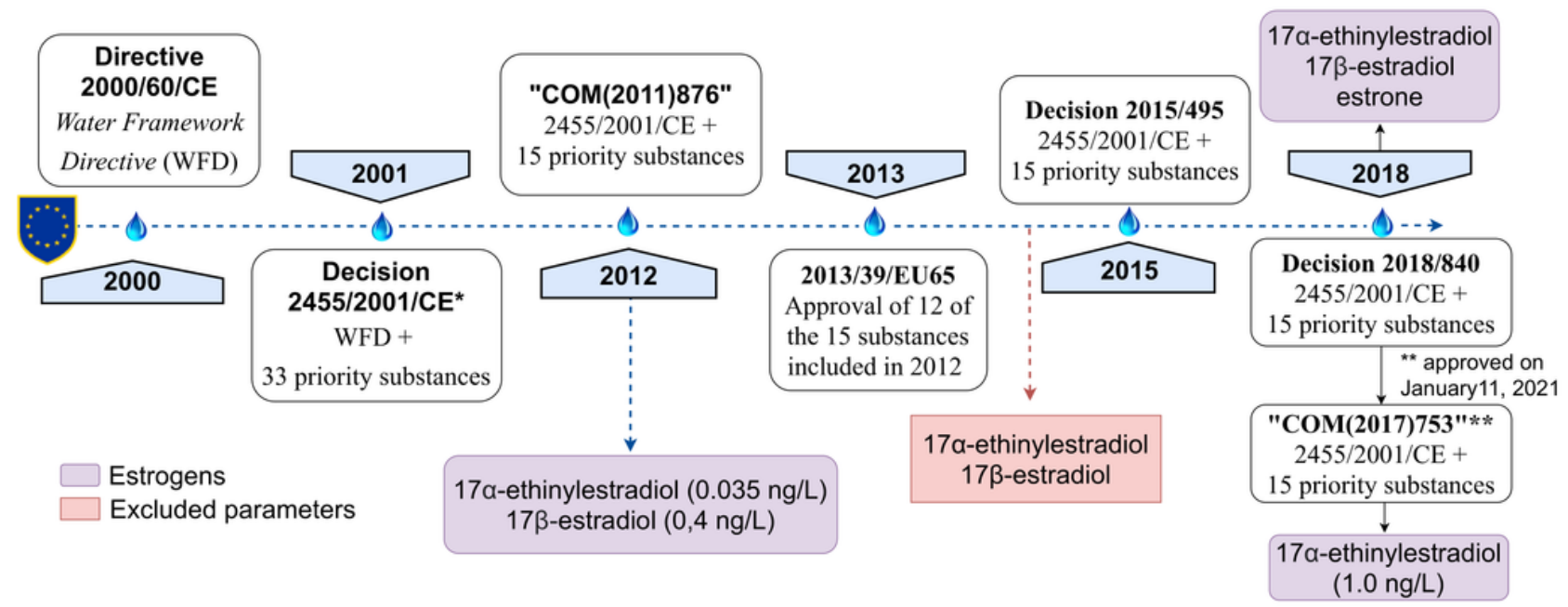

\section{Figure 2}

Timeline for European Union regulations published in 2000, 2001, 2012, 2013, 2015 and 2018, as well as the status of EDCs in each of these lists Source: data available in the Official Journal of the European Communities. $\left({ }^{*}\right)=$ the EDCs listed in the Decision 2455/2001/CE are listed in Supplementary Material 2. 


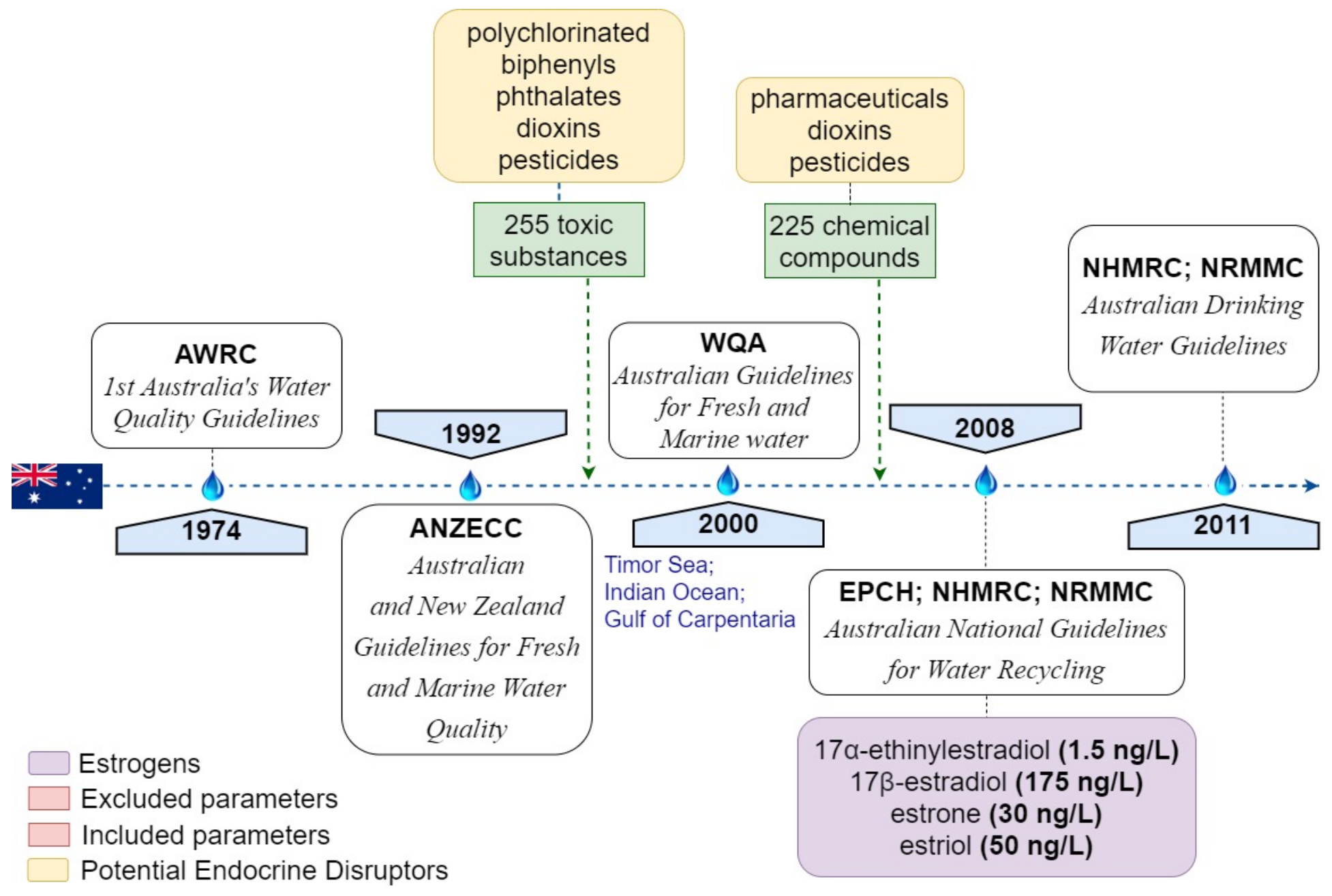

Figure 3

Timeline for Australian regulations published in 1974, 1992, 2000 and 2011, as well as the year of inclusion and maximum limits for estrogens in water recycling and drinking water Source: data available in the ADWG (NHMRC; NRMMC 2011).

\section{Supplementary Files}

This is a list of supplementary files associated with this preprint. Click to download.

- GraphicalAbstract.tif

- SupplementaryMaterial1.docx

- SupplementaryMaterial2.docx 